\title{
CORRECTIVE ACTION IN CAR MANUFACTURING
}

\author{
H Rohne' \& DC Page ${ }^{2}$
}

\begin{abstract}
In this paper the important issues involved in successfully implementing corrective action systems in quality management are discussed. The work is based on experience in implementing and operating such a system in an automotive manufacturing enterprise in South Africa. The core of a corrective action system is good documentation, supported by a computerised information system. Secondly, a systematic problem solving methodology is essential to resolve the quality related problems identified by the system. In the following paragraphs the general corrective action process is discussed and the elements of a corrective action system are identified, followed by a more detailed discussion of each element. Finally specific results from the application are discussed.
\end{abstract}

\section{OPSOMMING}

Belangrike oorwegings by die suksesvolle implementering van korrektiewe aksie stelsels in gehaltebestuur word in hierdie artikel bespreek. Die werk is gebaseer op ondervinding in die implementering en bedryf van so 'n stelsel by 'n motorvervaardiger in Suid Afrika. Die kern van ' $n$ korrektiewe aksie stelsel is goeie dokumentering, gesteun deur ' $n$ gerekenariseerde inligtingstelsel. Tweedens is ' $n$ sistematiese probleemoplossings metodologie nodig om die gehalte verwante probleme wat die stelsel identifiseer aan te spreek. In die volgende paragrawe word die algemene korrektiewe aksie proses bespreek en die elemente van die korrektiewe aksie stelsel geidentifiseer. Elke element word dan in meer besonderhede bespreek. Ten slotte word spesifieke resultate van die toepassing kortliks behandel.

1 H Rohne, BMW AG, 80788 Munich, Germany.

Tel: +4989 38246243, Fax: +498938242788, e-mail harald.rohne@bmw.de

2. *DC Page, Department of Industrial Engineering, University of Stellenbosch, Stellenbosch, South Africa.

Tel+2721 808434, Fax+2721 8084245, e-mail dcp@ing.sun.ac.za 


\section{INTRODUCTION}

This article is based on practical experience in implementing and operating a corrective action system in an automotive manufacturing company (BMW South Africa) situated in Pretoria. The research on which the article is based was carried out as part of thesis work for a Master's degree in Industrial Engineering at the University of Stellenbosch, Rohne [1].

BMW South Africa produces motor vehicles in the luxury market segment. It was established in 1975 and almost all models have since been built at this plant. Until recently, it was the only vehicle manufacturing plant of BMW outside Germany. Some five years ago, the plant assumed the responsibility for supplying cars for export, mainly to the Southern Hemisphere. In 1995, it produced the 3 series and 5 series models with a total volume of approximately 20000 units per year. More than 3000 employees where employed by the company at that time. With almost nine percent in 1994, BMW in South Africa enjoyed one of the highest market shares. In the same year it achieved the ISO 9002 certification.

Quality has been identified as the key to international and local competitiveness. This necessitates a change in attitude and behaviour and the understanding of quality. In the case of BMW South Africa the program to get the company listed under ISO 9002 provided the opportunity to implement an appropriate quality management system to change company culture. An important element in the system was Corrective Action. Although corrective action is reactive in nature, the structure it provides is vital for continuous improvement in the complicated automotive manufacturing environment.

Since South Africa re-opened to the world market and import and export activities increase, the local car manufacturing industry faces more competition. Import duties have been reduced, so brands manufactured in other countries have become more affordable for the customer. On the other hand quality aspects have come to the fore because the wide range of automobiles available in each market segment makes quality a deciding factor. Potential local decline in sales makes it essential to be able to export. In order to compete globally, one has not only to compete in new markets but also to conform to international requirements.

To appreciate these comments, the main differences between a developing country such as South Africa, and developed countries should be mentioned. They are the labour intensive manufacturing methods and the small volumes of production of each model. Labour is also relatively unskilled and not as well educated as in Western countries. The organised labour movement is very young and difficult to assess. These differences have a serious impact on the implementation of corrective action systems. Extensive training and education is for example required for teamwork for corrective action at the level where less sophisticated operators is involved.

\section{THE CORRECTIVE ACTION SYSTEM}

All the elements of a corrective action system interact in a certain way on the respective levels of detail shown in figure 1 . The identified problems result from measurements (for example: warranty or rework) which are documented in reports. Improvement teams or individuals take action based on the information. Verified and documented solutions show improvement in subsequent reports. The number of levels within reporting, documentation and the team structure are dependent on the complexity of information received, the size of the company and the knowledge and capability of the people involved. 


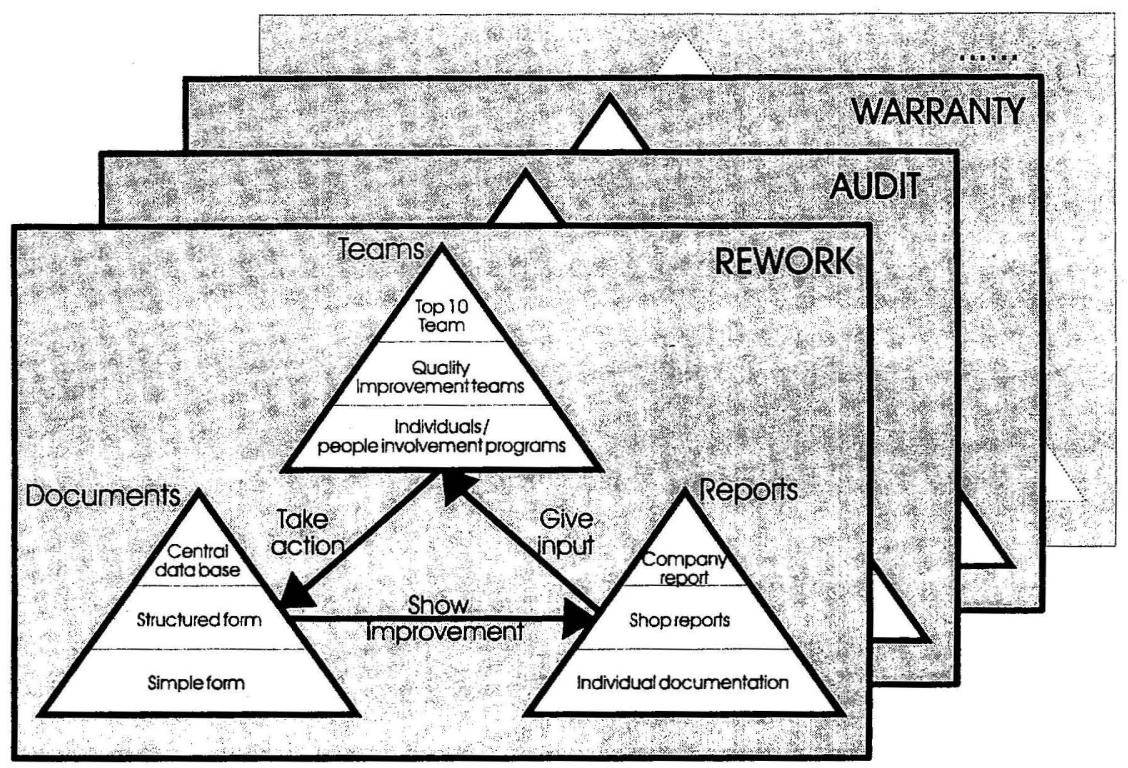

Figure 1 - Corrective action system elements

The elements of a corrective action system that have to be defined and implemented for successful quality improvement are:

- the identification of problems through measurements,

- a structure of problem reporting,

- an organisational structure for corrective action,

- the methodical approach to problem solving with

- tools and techniques, and

- the documentation of corrective action.

\section{MEASUREMENTS}

The identification of problems through measurement lays the foundation for a methodical approach. The information about quality - or non-quality, if defects occur - can be traced through the whole manufacturing process. Product and Process related sources of information are shown in Figure 2. Information on Product quality is collected as part of the feedback loop concerned with listening to the customer. It starts with the incoming parts inspection with the company as the customer of the supplier of parts. An internal customers may be a reworking production function (off-line or within the assembly line), or product audit functions along the line or at the end of the line. An external customer may be a dealer with problems experienced prior to delivery to the customer, or the ultimate customer. System and Process quality are monitored by various audits and by Statistical Process Control. All of these measurements are supported by a Quality Information System to allow flexible access to data. The focus, however, lies on the continuing measurement of product quality along the line of production, from the incoming part until the vehicle reaches the ultimate customer. 


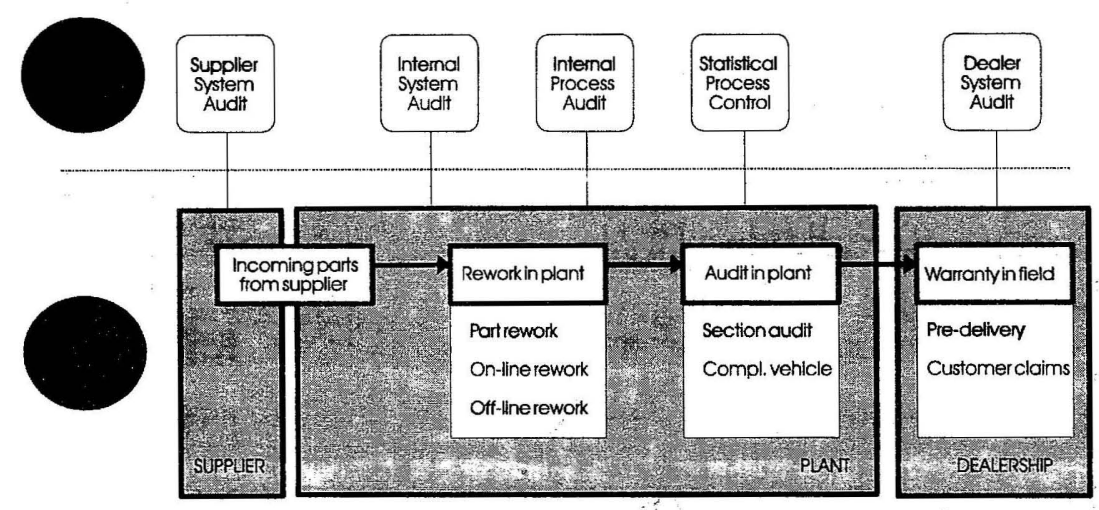

Figure 2 - Link between product quality measurements

For the initiation of corrective action, it is advantageous to have variable data to be able to qualify defects. As this is not possible by evaluation of numbers of defects, each measurement basically includes two standards of evaluation. One relates to occurrence (i.e. incidents), the other relates to weighing occurrence statistics based on the type of measurement. With this approach, the annoying factor of recurrence is taken care of, as well as the severity of a defect through the weighing factor.

\section{PROBLEM REPORTING}

Problem reporting should be hierarchically structured to ensure that each level in the organisation gets the right detail of information and acts accordingly. Because the reports must be consistent, quality reporting is a dedicated task for one department. Apart from the individual documentation, shop reports and a company report are to be distinguished, as shown in figure 1 . In the car manufacturing industry, shops, (for example Paint shop, Trim shop) represent the different steps in the production process. The shop reports are not designed to be pure management reports like the company report. They represent information management system supported communication between the quality division and the quality representatives in the production shops, production personnel and management. Based on the Pareto principle, the reports concentrate on the top problems for each type of measurement and shop. Statistics, information about new problems, responsibilities, solutions and implementation dates are added to the reports by the parties involved according to a set procedure. A PC-network gives the relevant persons the opportunity to extract information needed for topical and historical analyses at any time.

\section{ORGANISATIONAL STRUCTURE FOR CORRECTIVE ACTION}

The team structure for corrective action depends on the complexity of problems. For more sophisticated analysis and cross-functional resolution processes, higher profile personnel are required. The personnel involved can solve day-to-day problems. Therefore, individuals on the shop floor level are encouraged to take on problem solving activities, even if these are not part of a formal system. To support this drive, people involvement programs for quality improvement, supported by a coaching function, are appropriate for simple problems arising from daily work. 
Quality improvement team members are recruited from production line and middle management or engineer level. The teams are mainly concerned with process related problems within one production shop and resulting from their experience or rework activities. Although problem solving is a team approach, one team member is appointed champion for a problem. He or she must manage the activities around the corrective action process. From the skill level of middle management, which makes up these quality improvement teams, it can be expected that the process follow a methodical corrective action approach with defined steps.

Within the pyramid of corrective action teams, the Top 10 team is the highest level committee. It is concerned with the main quality targets of the company, which are reflected by repairs under warranty and product audit results. The team is guided by the Top 10 list of product quality problems. Its defined task, however, is not the one of a corrective action or quality improvement team, but of a steering committee. The quality division chairs the Top 10 team and its members are management representatives from the different shops and support functions. This also includes the marketing division representing the customer's voice. The team allocates a project leader with full authority and responsibility from management to approach the problem interdisciplinary. The project leader is supported with detailed information on the problem and with management decisions where required. He receives guidance in the corrective action steps necessary to implement a well-prepared long-term solution. Regular feedback to the Top 10 team and standardised documentation allow a safeguarded follow-up of activities.

\section{METHODICAL APPROACH TO PROBLEM SOLVING}

All of the various methods of continuous improvement and corrective action referred to in the literature (Asaka [2], Bemowski [3], Bhote [4], Kepner and Tregoe [5], Reliability Analysis Center [6]) lead to the same basic approach of systematic problem solving steps as used in the environment of car manufacturing. The key tasks are problem definition, analysis, solution, verification, followup and documentation, as shown in figure 3.

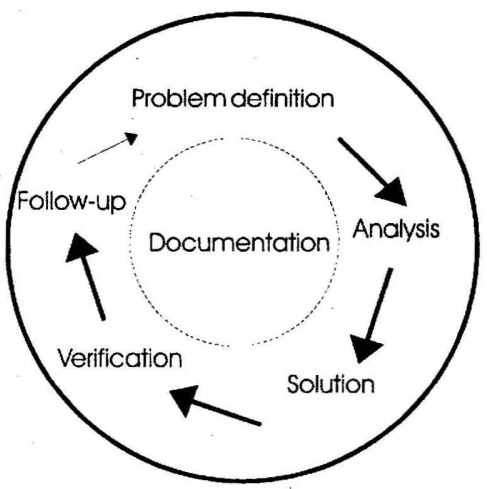

Figure 3 - The corrective action steps

The steps of problem definition and analysis are crucial to the success of corrective action. A problem has to be translated from the customer's interpretation into a technical description by an

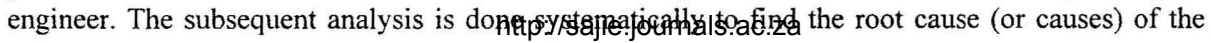


problem. Therefore it is important to use quality tools and techniques to ensure that a problem is correctly defined and all potential causes are taken into consideration.

In the solution phase it is necessary to distinguish between different actions. The check and fix of units already in the system, the immediate fix of all units to be built, the fix of the vehicles already in the field and the long-term solution in production, are typically subsequent steps. For all these activities and for the whole corrective action process, proper project management is necessary. This is only possible by allocating the problem solving project to a dedicated person who co-ordinates all involved parties and activities responsibly.

Medium- and long-term solutions should be verified by means of a test or pilot run before implementation. It is important to test the potential solution isolated from regular production in order to validate it before a trial and error approach causes further problems in production.

The follow-up of the problem is the last step in the corrective action loop, except for documentation, which is an ongoing activity. Depending on the ways and means of the follow-up it can be done immediately or in meaningful defined intervals later. It is recommended to do the follow-up check at least three times to ensure that the visible result is based on an improved and stable situation.

The bottom line of a corrective action system is a methodical approach to problem solving. With methodical corrective action, including supporting tools and techniques, a drastic reduction in problem solving time can be achieved. In addition to the advantages of reduced internal costs and improved quality leading to improved customer satisfaction, meaningful problem solving changes the attitude towards quality matters.

\section{TOOL AND TECHNIQUES}

To apply relevant quality tools, the quality division facilitates with diagnosis and coaching within the corrective action process. On the job training is preferable, since training without application is ineffective for corrective action activities. Appropriate tools are the seven management tools, statistical analysis, and Ishikawa diagrams, or failure mode and effect analysis (FMEA) for people on engineering or team leader level. Initially the introduction of the seven basic tools of quality to shop floor personnel works well. Some tools need to be applied on a regular basis as part of team approaches to get them accepted as part of standard practice in the company. Assistance in the application of more sophisticated techniques is provided by specialists from the Quality department. A tailor-made problem-solving manual for the company's corrective action methodology is useful to introduce the basic tools within each corrective action step.

\section{DOCUMENTATION OF CORRECTIVE ACTION}

The central role that documentation plays in the corrective action process is illustrated by figure 3 . In the production environment the hands-on approach and "we'll fix it"-thinking is commonly practised. But only documentation of the right type of information reduces duplication of activities resulting from missing communication or knowledge of activities of other personnel. Additionally, changes resulting from corrective action should be documented in an orderly way to be able to understand the actions at a later stage. This information is valuable for analysis of further problems in areas analysed previously. 
The suitable documentation for a car manufacturer is related to the three-tier report and team structure shown in figure 1. Simple forms support individuals in their problem solving. Structured forms, which illustrate the corrective action steps, support the quality improvement teams in production shops. It leads the team through the necessary tasks, while documenting agreed activities and the follow-up. A data processing system could support the communication of information on this form. For company wide cross-functional corrective action it is vital to store data on a computer system. Depending on the size of a company and the complexity of products and processes a longterm database is required to avoid repeatedly solving the same types of major problems. With such a database, knowledge of people who have moved or retired is recorded, so that junior engineers get information on past problems and their solutions.

\section{THE HUMAN FACTOR}

All the above mentioned approaches require involvement of people in a mature manner. This includes the capability of working in teams, commitment to the tasks and the empowerment to take decisions. A prerequisite for effective involvement in corrective action is sufficient intellectual capability of the person involved and a leadership style that motivates people to perform well (compare Gano [7]). It is the task of managers to encourage their subordinates in this regard by showing commitment to the process themselves. Once the foundation is created and the factors exist to an appropriate extent, the culture of ownership and responsibility can be fixed in employees. Education and training programs support this development in successful corrective action processes.

\section{DISCUSSION}

At BMW South Africa support was given to employees during initial implementation by several means. The concept of coaching during the whole process of problem solving, and a standardised procedure with defined targets for each step supplied an ideal guidance to effective problem solving. The coach introduced several basic quality tools to the team where appropriate. Tools were applied especially within the steps of problem definition and analysis. For example, descriptive graphs, Pareto analysis to prioritise problems, the $5 \mathrm{~W} 2 \mathrm{H}$-question-technique and the Ishikawa-diagram for analysis purposes. Other tools are applied and explained by the coach dependent on the specific situation. Specific tools are also recommended in an accompanying problem solving manual which guides the team through the process by means of a form to be completed for each step. Some problematical aspects of work ethics, however, came to light during the process, such as the habit to analyse problems exhaustively from several angles without progressing to the essential final steps of conclusions and implementation of the solution. Team members also found it difficult to understand that they are responsible for solving the problem without being blamed for the problem. These issues were addressed by management through mentorship and by recognition of employees' efforts.

This experience shows that a system of any kind can not simply be set up with the expectation that it will run, even assuming that the users of the system are motivated. The driving force provided by a strong champion of the system is essential. People involved also need organisational and administrative support in the form of stepwise recipes and aids during the initial phase to gain experience. This must be supplied together with long-term commitment to the process by management and the quality specialists within the company. 


\section{SUMMARY}

In conclusion, it was found that good coaches were vital in the process of changing the problem solving culture. Employees learned to do systematic problem solving and to use tools and techniques through application on the job. Presently, people want to be members of a problem solving team. Although the success cannot be pinpointed to the problem solving process only, it played an important role in achieving high market share and in improving internal and external product quality figures to an international level, establishing export capabilities.

The described methodical framework for a quality management system with operational corrective action processes is currently state-of-the-art procedure in South Africa and probably in most companies in the western world. To survive international competition, it is vital for companies to maintain efforts for continuous improvement, also by means of corrective action. In the complex and people-involving car manufacturing industry with constantly moving targets, quality has not yet reached - and might never reach - a level where a zero-defect production is realised with preventive action only. Corrective action, therefore, still improves product quality, contributing towards increased profit as the driving force for the existence of a company. References

\section{REFERENCES}

[1] Rohne H, 1996, "The implementation of a corrective action system for product quality improvements at an automotive manufacturing plant", unpublished Master's in Engineering thesis, Department of Industrial engineering, University of Stellenbosch, 208pages.

[2] Asaka T (ed.), 1990, "Handbook of Quality Tools", Cambridge, Productivity Press.

[3] Bemowski K, 1994, "Ford Chairman was, and continues to be, a Progress Chaser", Quality Progress, October 1994, pp.29-32.

[4] Bhote KR, 1991, “World Class Quality”, New York, American Management Association.

[5] Kepner CH, Tregoe BB, 1978, "Analytic Trouble Shooting", 3rd edition, Princeton, KepnerTregoe.

[6] Reliability Analysis Center, 1992, "Introduction to Concurrent Engineering: Electronic Circuit Design and Production Application", New York, Rome Laboratory.

[7] Gano DL, 1994. "Total Failure Management", Quality Digest, November 1994, pp.56-61. 